\title{
Causative Constructions in Afaan Oromoo: Formal and semantic perspectives
}

\author{
Eba Teresa Garoma * \\ (Jimma University, Ethiopia) \\ Girma Tesfaye Tekle ** \\ (Mizan-Tepi University, Ethiopia)
}

\begin{abstract}
The main objective of this study is to give descriptions of formal and functional aspects of causative constructions in Afaan Oromoo. To achieve the objective, written texts, native speaker informants and introspections are predominantly used as sources of data. The findings reveal that the three structural aspects of causatives- morphological, lexical and syntactic- are used in the language. Morphological causatives are highly productive, and affixes with $-s$ and $-i$ in several combinations as well as -eess are employed for such purposes. Causative Morphemes are detected to derive causatives of basic verb stems of different semantic categories and to involve causations in word-class changing. There are also simple and complex causations in which there are several causatives suffixes, causers and micro-events indicated morphologically and syntactically. Semantically, direct, indirect, and assistive/cooperative causatives are identified. Pseudo-causatives are uncovered as peculiar futures of the language too. There are, even, structures with explicit causative affixes which are called subjectless causatives, but they do not show any causal relations between the participants in the structure.
\end{abstract}

Keywords: Afaan Oromoo, morphological causatives, direct vs. indirect causatives

\section{Introduction}

The Oromoo are one of the Cushitic-speaking people living in Ethiopia, but also in neighboring countries, mainly Kenya and Somalia. In Ethiopia, the Oromoo people account for $34.5 \%$ of the total population, i.e., for approximately 32.5 million speakers (CSA, 2007). This makes them one of the most numerous people in Africa (Kebede, 2009; Debela, 2010). In addition to the huge number of mother tongue speakers, Afaan Oromoo is also acquired as a second language for inter-group communication. It is written with a modified

\footnotetext{
* Eba Teresa Garoma: Associate Professor of Linguistics, Department of English Language \& Literature, Jimma University, Ethiopia. E-mail: ebateresa@gmail.com.

** Girma Tesfaye Tekle: Lecturer, Mizan-Tepi University, Ethiopia. E-mail: gttone@gmail.com.
} 


\section{Causative Constructions in Afaan Oromoo: Formal and semantic perspectives}

Latin alphabet known as Qubee [k'ube:]. Currently, Afaan Oromoo is widely utilized in the mass media (radio, television and newspapers), serves as medium of instruction in primary and secondary schools in the Oromia Regional State, and is a field of study in colleges and universities (Yabe, 2007).

The Oromoo language (self-name Afaan Oromoo, lit. 'mouth of the Oromoo') belongs to the Lowland East Cushitic language family (cf. Mous, 2012). There are several Afaan Oromoo dialects, which are commonly clustered based on their geographical distribution: Northern (Wollo-Raya), South-Eastern (Arsi-Guji-Borana), Eastern (Harar/Barentu), and West-Central (Macha-Tulama) (Kebede, 2009:1; Tolemariam, 2009:6; Debela, 2010:4-5). The current study deals with the Macha dialect.

\section{Statement of the problem}

Causative constructions are central issues of human conceptualization because every human language seems to possess means of expressing them (Comrie, 1989:165; Shibatani, 2001:1; Stefanowitsch, 2001:345). These may provide important insights in the cognitive perspectives of speakers, as they describe a complex macro-event consisting of several participants engaged in various sub-events (micro-events). Morphologically, causative constructions involve affixes indicating the nature of causation and the respective agents. Syntactically, they trigger changes in the verb valence, i.e. in the number of arguments. They also specify the temporal and physical involvement of the causers (Comrie, 1981:160).

With regard to Afaan Oromoo, a few studies were conducted on causative constructions, which generally show that lexical and syntactic causatives are very productive, whereas the morphological causative is rather peripheral. Owens (1985) deals with causatives from the lexical grammar perspective concluding that Afaan Oromoo causatives are constructed without lexical rules. Dubnisky, Lloret \& Newman (1988), in contrast, treat morphological causatives as syntactic structures. They reject the contributions of affixes for valency changing, and completely neglect semantic (functional) aspects of causative constructions. Recently, Tolemariam (2009) gives an overview of Afaan Oromoo causative constructions as subsection of his $\mathrm{PhD}$ dissertation. He primarily deals with morphological causatives and their semantic categories, but excludes lexical and syntactic causatives. The relation between causative affixes and the agents of the macro- and micro-events are also not considered.

In contrast to these studies, the present study attempts a more comprehensive description of Afaan Oromoo causative constructions from the two major typological perspectives: formal (structural) and semantic (functional). The analysis is based on data, which were extracted from written texts (novels): godaannisa, gurraattha abbajjaa, jeroon siif 
haadiistu and hawwii, textbooks and checked through elicitation with native speakers, and through introspections. The data were categorized into specific causative types, whose formal and semantic features are discussed in the following sections.

\section{Objectives of the study}

The main objective of this study is exploring formal and semantic features of causative constructions in Afaan Oromoo. The followings are specific objectives: (a) Identifying morphological forms of causative constructions; (b) Distinguishing lexical and syntactic causatives; (c) Showing semantic features of causatives.

\section{Conceptual framework: typological features of causatives}

Causative construction can be defined at the most general level as any construction encoding a causative situation: two events occurring in temporal succession, where the speaker believes that the second event would not have happened if the first event had not happened. Moreover, a causative construction involves minimally two participants: the causer and the causee. It is a valence-increasing process that shows a subject causing another entity to do something, or causing a change in state. This process prototypically adds a new argument (the causer) to a transitive verb, demoting the original subject to an object. Languages can express causation through lexical, morphological and syntactic means, which may differ in their productivity. Often, these causative devices can be linked to specific semantic meanings (Comrie, 1989:167; Kulikov, 2001:886). Causative constructions are derived through three aspects, of which either some or all can be found in a language: Lexical, morphological and syntactic causatives.

Lexical causatives are based on the verb semantics, which mainly denotes the straightforward physical involvement of a subject (agent) with high degree of animacy directly affecting another participant (object/patient). As causation is an inherent semantic property of the verbs, there are no overt morphological or syntactic devices that indicate causation in such causation (Shibatani, 1973:282; Wierzbicka, 1980; Comrie, 1989:168; Lemmens, 1998:3-4; Kulikov, 2001:887).

Morphological (synthetic) causatives are constructions in which the causative morpheme is an affix that attaches to a basic verb or any other stem. In most languages of the world, morphological causatives can be derived from all types of verbs: intransitive, ambitransitive, transitive and ditransitive. The morphological causative typically increases the valence of a verb by one, and is the most productive construction for causativization (Comrie, 1989:167-75; Kulikov, 2001:886; Shibatani, 2001:6-7; Escamilla, 2012:57).

Syntactic (analytic, periphrastic) causatives are constructions in which the causative morphemes are free forms, particularly verbs having the meaning of cause, make, order, etc. 


\section{Causative Constructions in Afaan Oromoo: Formal and semantic perspectives}

In contrast to lexical and morphological causatives, the syntactic causative involves two clauses: A separate predicate which expresses the process of causation (macro-event), and another predicate denoting a micro-event. Although syntactic causatives are common in most languages, they are infrequently used (Comrie, 1989:167; Kulikov, 2001:886; Shibatani, 2001:16).

The semantics of causative constructions is associated with an agent causing another participant to do an action or to be in a certain condition. Thus, they denote a relation between two events in which the occurrence of one event (micro-event) is realized due to the trigger of the other (macro-event). Accordingly, causative constructions are classified into several functional types based on the nature of the actions or events involved, e.g. direct vs. indirect, assistive and declarative causatives, which can be expressed through any of the three structural types - lexical, morphological or syntactic (Talmy, 2000; Kulikov, 2001:891-2; Shibatani, 2001:11).

In the distinction between direct and indirect causatives, the mediacy of the relationship between cause and effect is the main concern. In the direct causative, cause and effect are temporally close to one another; usually, it is challenging to split macro-event and micro-event physically into cause and effect though the conceptual understanding reveals the two. In indirect causatives, the causer is not directly involved in bringing about the effect; hence, there is manipulation of the cause through distant causation (Comrie, 1989:172; Kulikov, 2001:892).

Assistive (cooperative) causation is a construction in which the causer helps the causee to bring about a change in the state of affairs. It is a pseudo-causative because it has no meaning of cause in the strict sense despite rendering the same marker as true causatives in some languages (Kulikov, 2001:892). Another pseudo-causative construction is the declarative causative which expresses that the causer speaks about the caused event as if it could bring about a hypothetical change in the state of affairs (Kulikov, 2001:893).

\section{Research methodology}

This study deals with structural and functional aspects of causative constructions in Afaan Oromoo. In order to achieve this goal, data were collected from written texts, such as Afaan Oromoo textbooks of grades 7-12, novels, namely Godaannisaa, Gurraacha Abbayaa, Hawwii and Yeroon Siif Haa Dhiistu ${ }^{\mathbb{D}}$. Besides, native speakers and language teachers were requested to judge the acceptance of the expressions. The native speakers were selected using snowball sampling technique since one informant suggests the next on the basis of intuition about the language. Moreover, introspection was also used as an

\footnotetext{
(1) The names of the novels are written in Afaan Oromoo orthography.
} 
alternative source in some respects. Expressions which contain causative structures were collected from these sources using purposive sampling. Then, the data were refined and presented using morphological annotation, glossing and equivalent English translation. Finally, discussion was made using structural and semantic description of the data at hand.

\section{Causative constructions in Afaan Oromoo}

Afaan Oromoo applies the three aspects of causative constructions: lexical, morphological and syntactic. While morphological causatives are highly dominating, lexical and syntactic causatives are used as peripheral constructions. As lexical causatives depend on the inherent natures of the lexical elements, very few verbs reveal this, but syntactic causatives occur in the language based on the intensities of the events and the explicit descriptions of causers in the micro-events.

\subsection{Morphological causatives}

Morphological causative is the most productive type of causative constructions in Afaan Oromoo. Based on their combinability with certain semantic verb classes (e.g. agentive intransitive, non-agentive intransitive, and transitive verbs) and phonological factors, simple and complex causative suffixes were identified, which mark distinct functional types of causation (cf. also Dubnisky, Lloret \& Newman, 1988; Tolemariam, 2009): the auffixes are $-s\left[\right.$ CAUS $^{1}$ ], -is [CAUS ${ }^{2} / \mathrm{CAUS}^{7}$ ], -iis [CAUS ${ }^{3}$ ], -sis [CAUS ${ }^{4}$ ], -siis [CAUS ${ }^{5}$ ], and -eess $\left[\mathrm{CAUS}^{6}\right] .{ }^{1}{ }^{1}$ The combinations of some of these causative suffixes derive complex morphological causations which mainly include double and triple causatives.

\subsubsection{Simple causatives}

Simple causatives are forms which involve only single suffix to derive morphologically causativized structures. In such causations, non-causativized intransitive, inchoative stative and transitive verbs show increase in valences/arguments. These are formed in two ways. The first type is indicated when the causative constructions are derived from certain verb stems. These causations are categorized based on the phonological natures of the stems. The second types are word-class changing causative derivations. These are basically causative morphemes which change adjectives, nominals and ideophones into causativized verbs.

6.1.1.1 Causative derivation of basic verb stems

Causative derivation of verb stems involves two groups of causative suffixes based on the phonological natures of the stems. These are $-s$ and $-i s$ [CAUS ${ }^{1}$ and CAUS ${ }^{2}$, and $-s i s$ and -siis [CAUS $^{4}$ and CAUS $^{5}$ ]. Illustrations of these causations are provided as follow.

\footnotetext{
(1) We use phonetic transcription which is almost the same as Oromo orthography: double vowel shows lengthening and double consonant shows gemination in a word.
} 


\section{Causative Constructions in Afaan Oromoo: Formal and semantic perspectives}

\subsection{Causative suffixes $-s$ and $-i s$ [CAUS ${ }^{1}$ and CUAS $^{2}$ ]}

The first group of causative derivation involves the basic stems of inchoative-stative and non-agentive intransitive verbs having $\mathrm{CV}(\mathrm{V}) \mathrm{C}$ or CVC. The suffixes $-s\left[\mathrm{CAUS}^{1}\right.$ ] and $-i s$ [CAUS ${ }^{2}$ ] are added to the verbs with these stems respectively, and derive transitive/ causative verbs with causer or agent as external subject. The following examples show such causation.

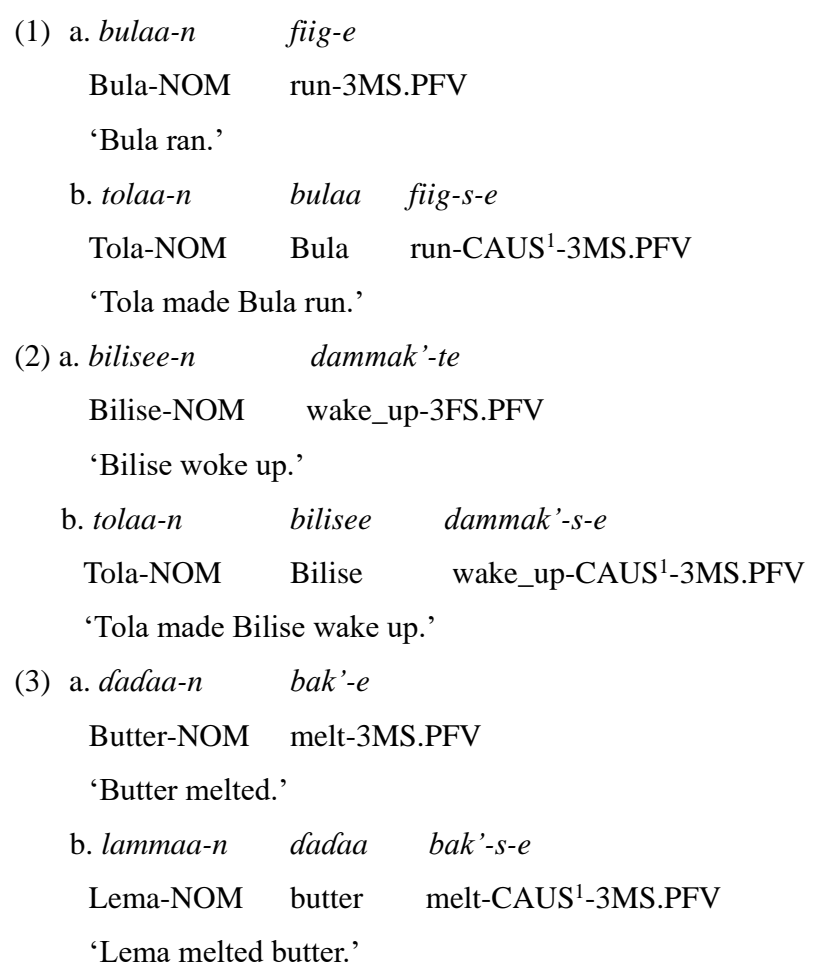

(4) a. mut'aa-n raf-e

baby-NOM sleep-3MS.PFV

'The baby slept.'

b. tolaa-n mut'aa raff-is-e

Tola-NOM baby sleep-CAUS ${ }^{2}$-3MS.PFV

'Tola made the baby sleep.'

(5) a. bun-ni danf-e

coffee-NOM boil-3MS.PFV

'The coffee boiled.'

$\begin{array}{cll}\text { b. } \text { bulaa- } n & \text { buna } & \text { danf-is-e } \\ \text { Bula-NOM } & \text { coffee } & \text { boil-CAUS } 2 \text {-3MS.PFV }\end{array}$


'Bula boiled coffee.'

The sentences listed in (a) under (1-5) show non-causative verbs: fiig- 'run', dammak''wake up', bak'- 'melt', raf- 'sleep' and danf- 'boil'. When the suffixes $-s$ and -is are attached to these forms, they derive causativized verbs listed in (b) under (1-5). The distribution of $-s$ and $-i s$ seems to be phonologically conditioned as the former is attached to $\mathrm{CV}(\mathrm{V}) \mathrm{C}$ verb stems and the later to CVCC in which the vowel $-\mathrm{i}$ would be epenthetic to avoid three consonant clusters. With regard to the semantic categories of the stem verbs, the causativized verb fiig- 'run' in (1) is motion event, and bak'- 'melt' in (3) inchoative-stative as it denotes a change into a new state while dammak'- 'awake' in (2) shows remaining in a state. Besides, the causativization of the intransitive verbs changes them into transitive verbs with a new subject argument as causer, i.e. tolaa 'Tola', lammaa 'Lema' and bulaa 'Bula' are causers of macro-events. Intransitive verbs such as dab'bend', gog- 'dry', diriir- 'spread' have similar causativization patterns with the above examples. However, there are few exceptions in which the rules do not work. Some verbs with similar stem $(\mathrm{CV}(\mathrm{V}) \mathrm{C}$ and $\mathrm{CVC})$, such as deem- 'go' are causativized differently as shown in the next section. These might have happened due to certain special morphophonemic triggering factors.

6.1.1.1.2 Causative suffixes -sis and -siis [CAUS ${ }^{4}$ and CUAS $^{5}$ ]

The causatives in this category involve intransitive agentive verbs with CVVC and CVCC, which are changed into transitive verbs with causer subjects. The suffixes seem to be phonologically-conditioned: when a stem ends with closed syllable (CVVC), the suffix -sis is used, and when the final syllable has short vowel (CVCC or CVC), the suffix -siis is used in causativization.

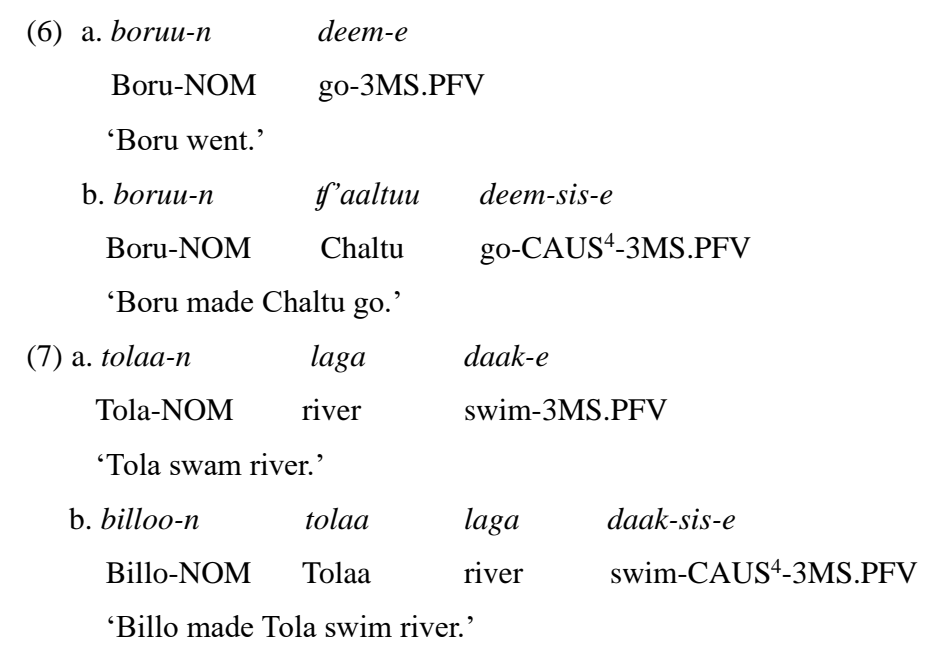


The example in (6a) contains the verb stem deem- 'go', which is agentive intransitive. The causative form of such agentive intransitive verb attaches the suffix -sis in (6b). There seems phonological triggering factor as this suffix is attached to the stems with long vowels word-medially. It is a simple/single causative suffix, which is completely different from -s-is (double causative). The example in (7) follows the same pattern to derive the causative verb daak-sis 'make swim'.

The causative suffix -siis $\left[\mathrm{CAUS}^{5}\right.$ ] is another simple causative form. The stems have short vowels word-medially, and mostly gemination or consonant cluster word-finally, except in few cases, such as bar- 'know', where germination of trill is not allowed before sonorant. Examples are given below.

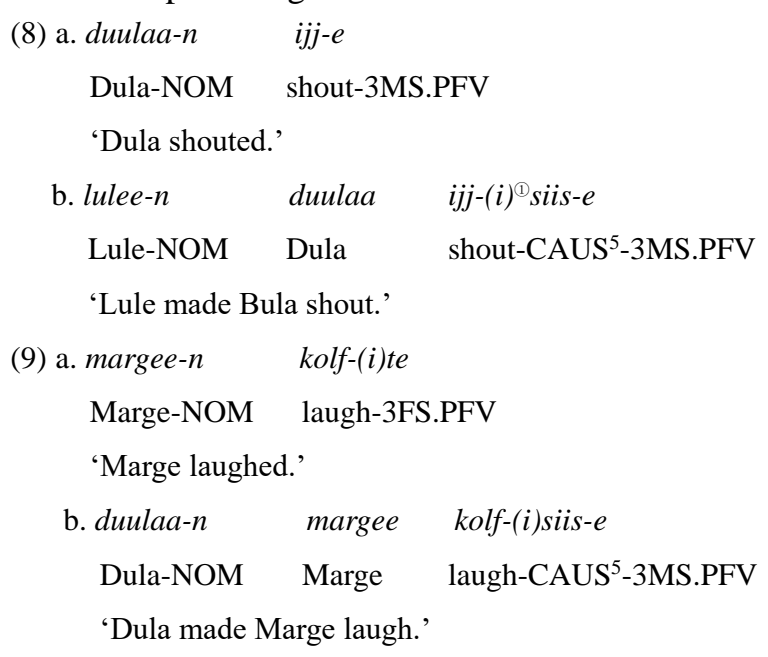

The examples in (b) under (8) and (9) show the causativized forms of intransitive agentive verbs listed in (a) above: ijj- 'shout' and kolf- 'laugh'. The suffix -siis is completely different from -sis in its occurrence in verbs despite both being single causative suffixes. As the verbs are causativized, there is valence-increasing parallel to the causativizer, following similar patterns. There are also syntactic demotions because the subjects of non-causativized verbs become objects in the process: duulaa 'Dula' in (8b) and margee 'Marge' in (9b).

The causative suffixes - sis $\left[\mathrm{CAUS}^{4}\right]$ and - siis $\left[\mathrm{CAUS}^{5}\right]$ can also be attached to transitive verbs with $\mathrm{CV}(\mathrm{V}) \mathrm{C}$ and $\mathrm{CVCC}$ stems. Illustrations of each of these causatives are provided below.

$$
\begin{array}{rll}
\text { (10) a. t'aaltuu- } n & \text { gurbaa } & \text { reeb-de } \\
\text { Chaltu-NOM } & \text { boy } & \text { hit-3FS.PFV }
\end{array}
$$

\footnotetext{
(1) The vowel $i$ is epentheticized to keep consonant clusters.
} 
Eba Teresa Garoma \& Girma Tesfaye Tekle

'Chaltu hit the boy.'

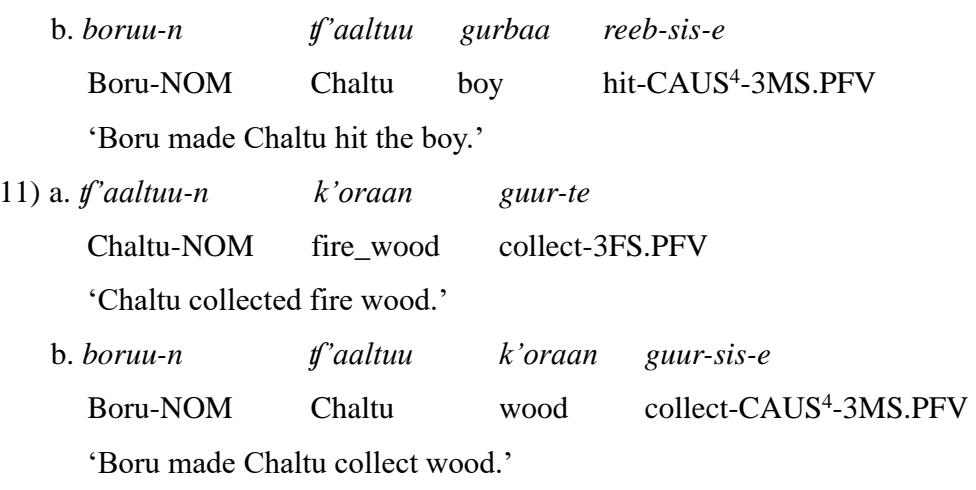

The examples in (10a) and (11a) are structures with non-causativized transitive verbs: reeb- 'hit' and guur- 'collect' respectively. These verbs have CVVC stem structure, and most non-causativized transitive verbs of such type attach the suffix -sis to show causativized structures. However, verbs of the same semantic category with different radicals (CVC, CVCC or any other) attach -siis, which is phonologically-conditioned form of -sis. The following examples show causativization of the verbs with CVC and CVCC.
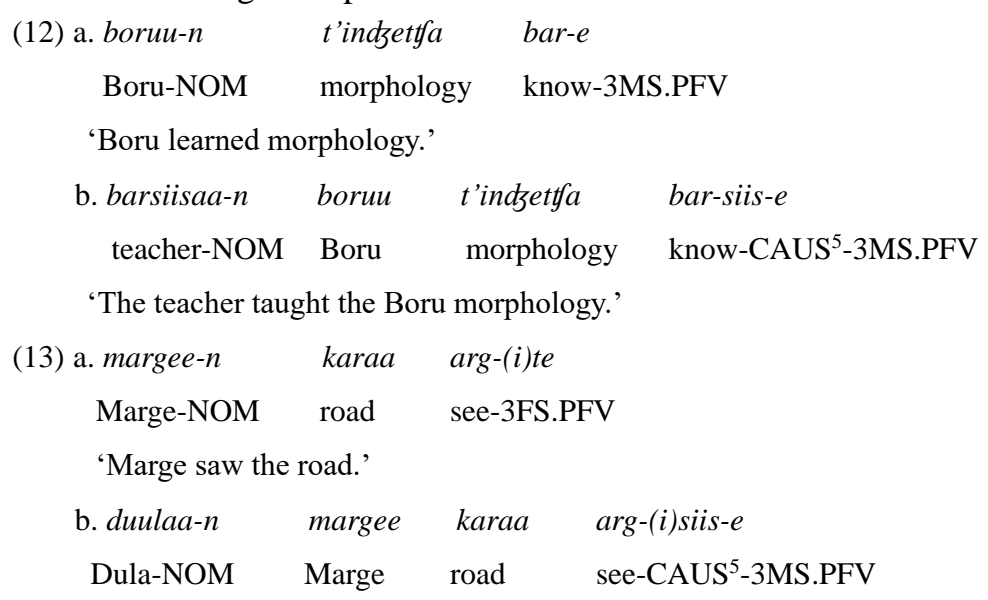

'Dula showed Marge the road.'

The transitive verbs bar- 'know' and arg- 'see' in examples (12a) and (13a) have CVC and CVCC stem structures, respectively, and they both attach the suffix -siis to derive the causative forms of the verbs. Along with the causative suffixes, there are agents/causers of the macro-events which are added as subjects of the sentences.

6.1.1.2 Word-class changing causative derivation

In Afaan Oromoo, causativization also involves derivations with word-class changing. The causative suffixes -eess $\left[\mathrm{CAS}^{6}\right]$ and -is $\left[\mathrm{CAUS}^{7}\right]$ are principally used for such purpose. 
The first suffix (-eess) is attached to adjectival and nominal stems to derive causative structures/verbs. The causative suffix -(e)ess has two occurrences: it is -eess when the stem has CVC, and -ess when the stem is CVVC. The second (-is) is mainly attached to adjectives with CVCC stems to form causative structures.

The suffix -eess is different from the other causative forms in two aspects. The first difference lies on its phonological structure; it has long $e$ and geminated $s$, unlike others. Another difference is on the stems of the lexemes; -eess is suffixed to nominal and adjectival stems only (Tolemariam, 2009:14). This suffix is quite unique in that it has no any possibility to be affixed to transitive or intransitive verb stems. The following examples illustrate causativization through suffixation of -eess.

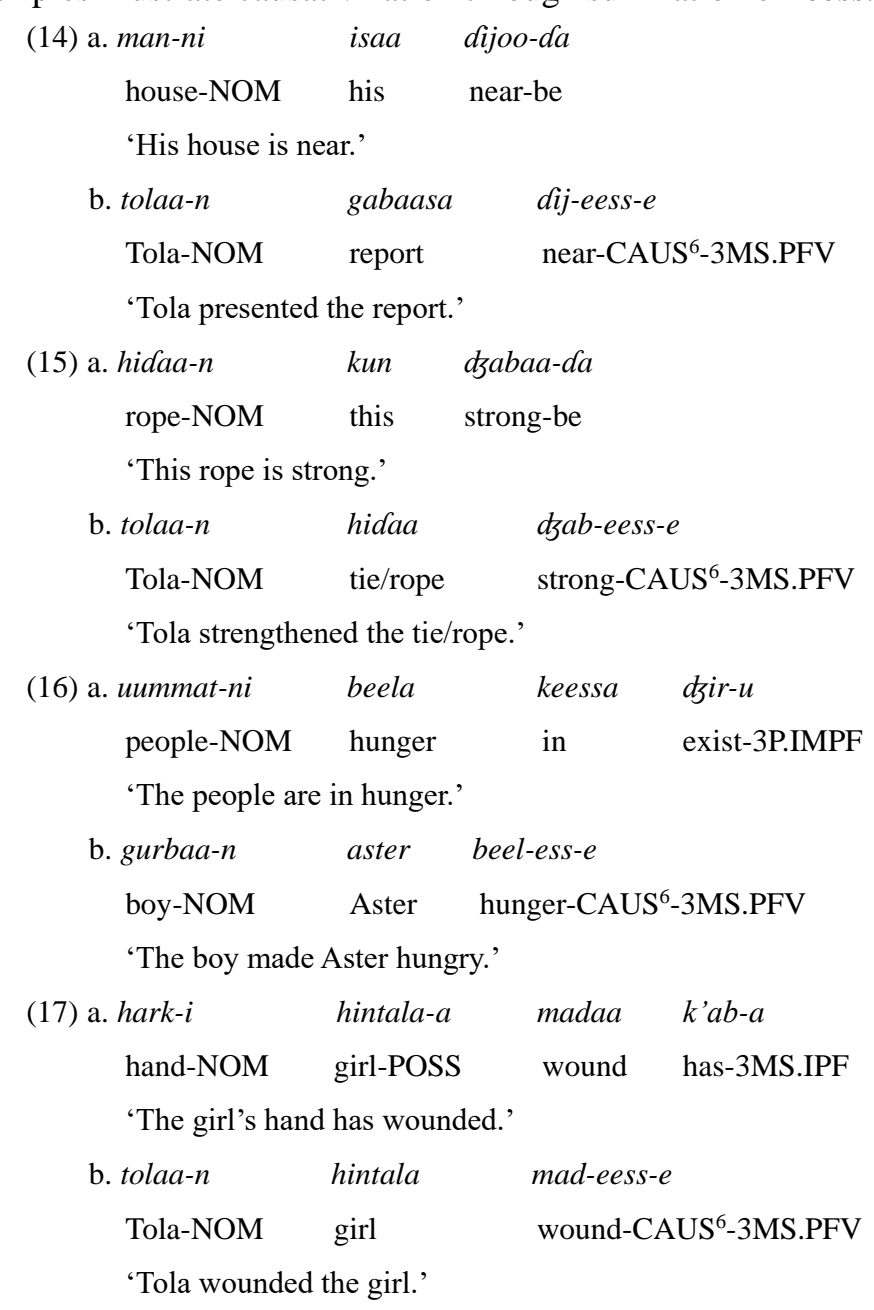

The examples in (14a) and (15a) have adjectival stems dijoo 'near' and d3abaa 'strong', 
which are non-causativized forms. These stems are causativized to dij-eess- 'present' and dzab-eess- 'strengthen' through suffixation in (14b) and (15b) respectively. In (16a) and (17a), the stems beela hunger' and madaa 'wound' are nouns. When the suffix -ess is attached to the first nominal stem beel- 'hunger', it derives causative verb beel-ess- 'make someone hungry'. The phonological structure of the stem is CVVC so that it takes the suffix with short vowel: -ess. The nominal stem mad- 'wound' attaches the causative suffix -eess as its structure is CVC: mad-eess- 'make someone wounded'. There is also valence-increasing (causer subject) along with the suffixation for the macro-events.

Another word-class changing causative suffix is -is $\left[\mathrm{CAUS}^{7}\right]$, which involves adjectival stems having CVCC phonological structures. The suffix is homophonous with -is [CAUS ${ }^{2}$ ], but it is suffixed to adjectival and ideophonic stems where as -is [CAUS $\left.{ }^{2}\right]$ is attached to verb stems. The causativization of adjectives and ideophones is shown below.

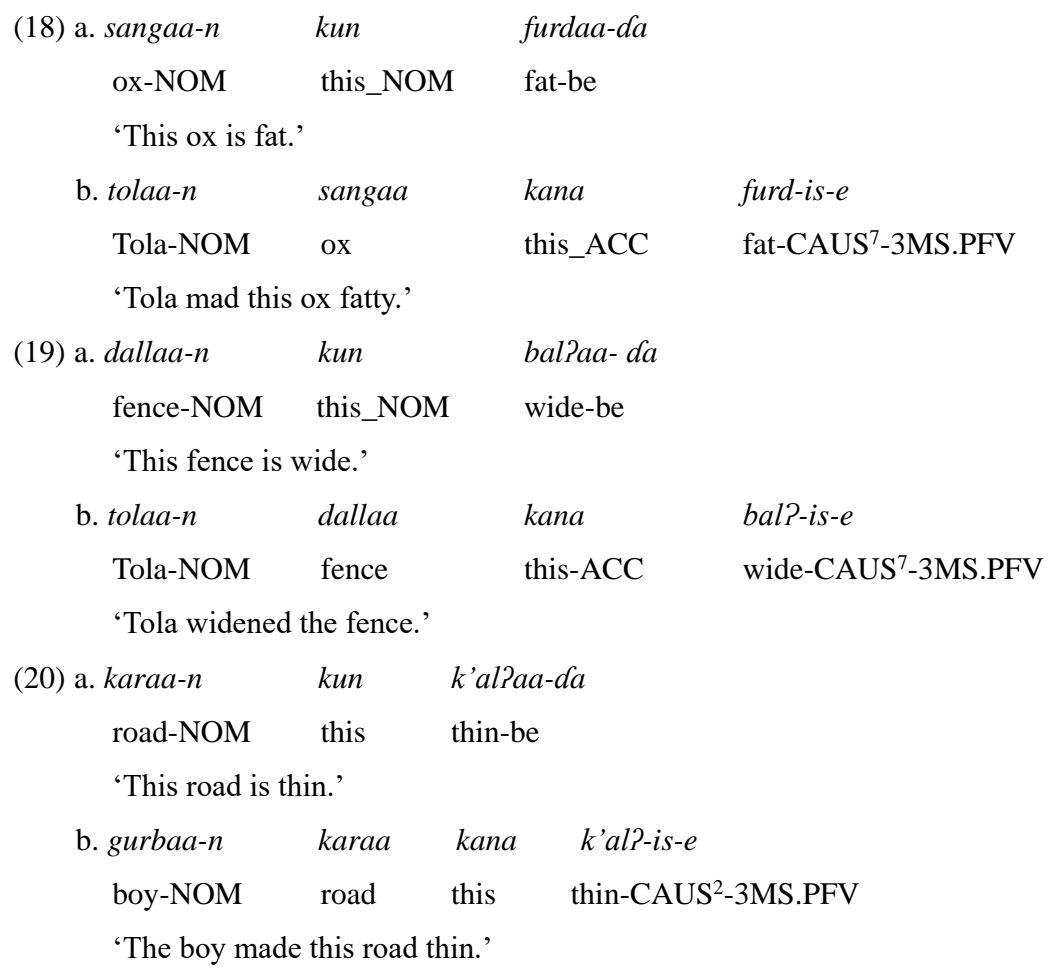

The examples listed above illustrate the causativization of adjectives, which have CVCC structure in their stems. The causativized verbs denote change of state or size of the entities in the micro-events through the force of the subjects/agents of macro-events. For example, in the action of furd-is-e 'made fat' (example (18b)), an entity which was not fat before the causativization becomes fat after the process. Thus likewise, there are changes in the states 


\section{Causative Constructions in Afaan Oromoo: Formal and semantic perspectives}

of existence of entities/arguments mentioned above through the process.

Ideophones are another stems which are verbalized as agentive intransitive verbs through the causative suffix - is $\left[\mathrm{CAUS}^{7}\right]$. These following examples illustrate causativization of ideophones.

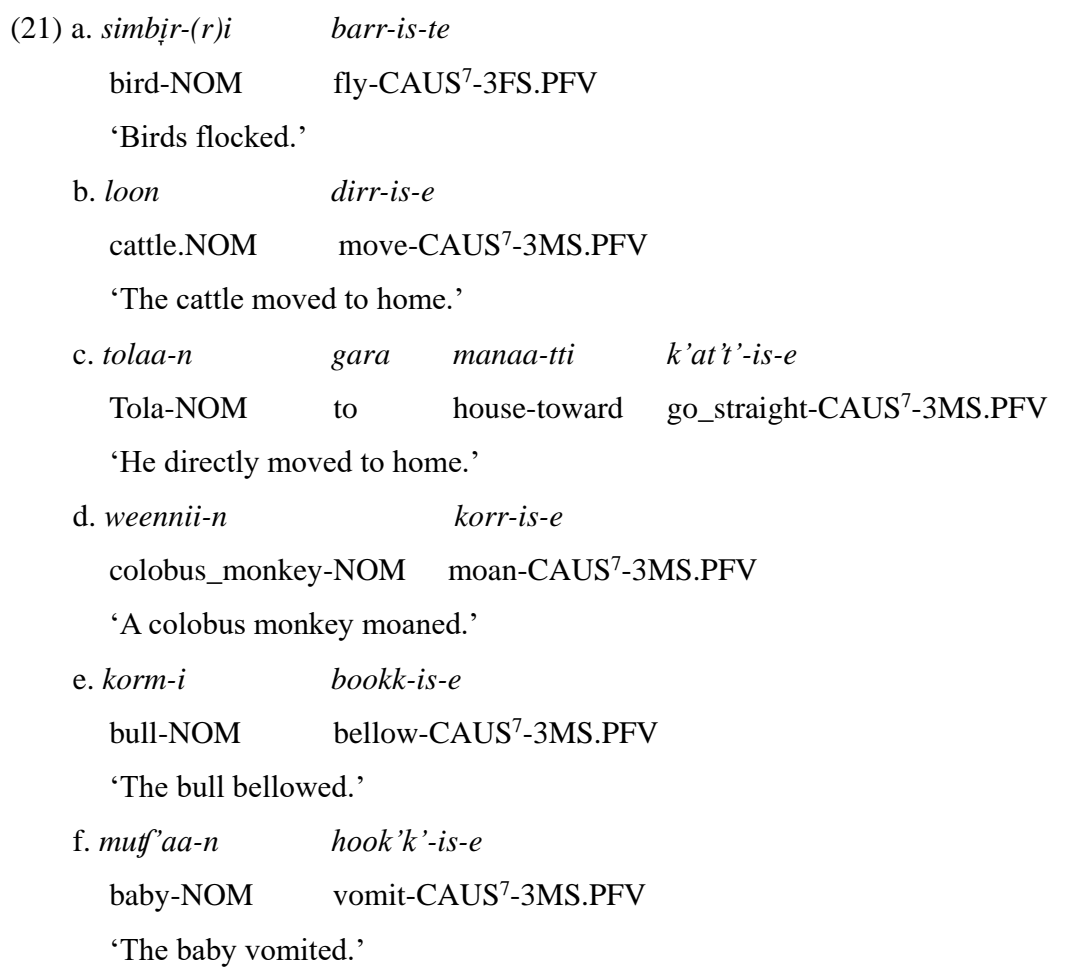

The examples listed in (21a-f) show the causativization of ideophones by the attachment of the suffix -is $\left[\mathrm{CAUS}^{7}\right]$. As the actions indicated in the causativized verbs are accomplished on the subjects/agents, they are called intransitive causatives. The intransitive causatives formed in (21a-c) (barr-is 'flock', dirr-is 'move' and k'at't'-is 'move') are semantically categorized as motion verbs because they show movement of the subjects/agents, and the ones in (21d-e) are sound emission verbs as the subjects produce sound: korr-is 'moan' and bokk-is 'roar'. However, the example in (21f) shows movement of digested food outside the body through mouth; yet there is motion event happening on the subject. In all cases, the causative structures formed through causativization have only one subject each, which acts upon the action indicated in the intransitive causative verbs despite the presence of causative marking suffix -is. Thus, there is no valence-increasing as the causer is self-agentive subject.

\subsubsection{Complex causatives}


Complex causatives are morphological causatives which involve double and triple causative structures that are derived from the combination of different single/simple causatives. The attested double causative constructions are $-s+-i i s$ [CAUS ${ }^{1}+\mathrm{CAUS}^{3}$ ], -is+-iis [CAUS ${ }^{2}+\mathrm{CAUS}^{3}$ ], and $-s+-i s$ [CAUS ${ }^{1}+\mathrm{CAUS}^{2}$ ], while there is only one triple causative construction: $-s+-i s+-i$ is [CAUS $^{1}+\mathrm{CAUS}^{2}+\mathrm{CAUS}^{3}$ ].

6.1.2.1 Double causative $-s+-$ iis [CAUS $^{1}+\mathrm{CAUS}^{3}$ ]

The double causative with $-s+-i i s\left[\mathrm{CAUS}^{1}+\mathrm{CAS}^{3}\right]$ is formed through two processes one after the other. The non-causativized stems are mainly intransitives. Accordingly, the double causative suffix $-s+$-iis shows two macro-events; it is first derived from non-causative verbs by adding causer subject/argument and suffixing $-s$. Then, the causer of the macro-event and the suffix -iis follow sequentially.

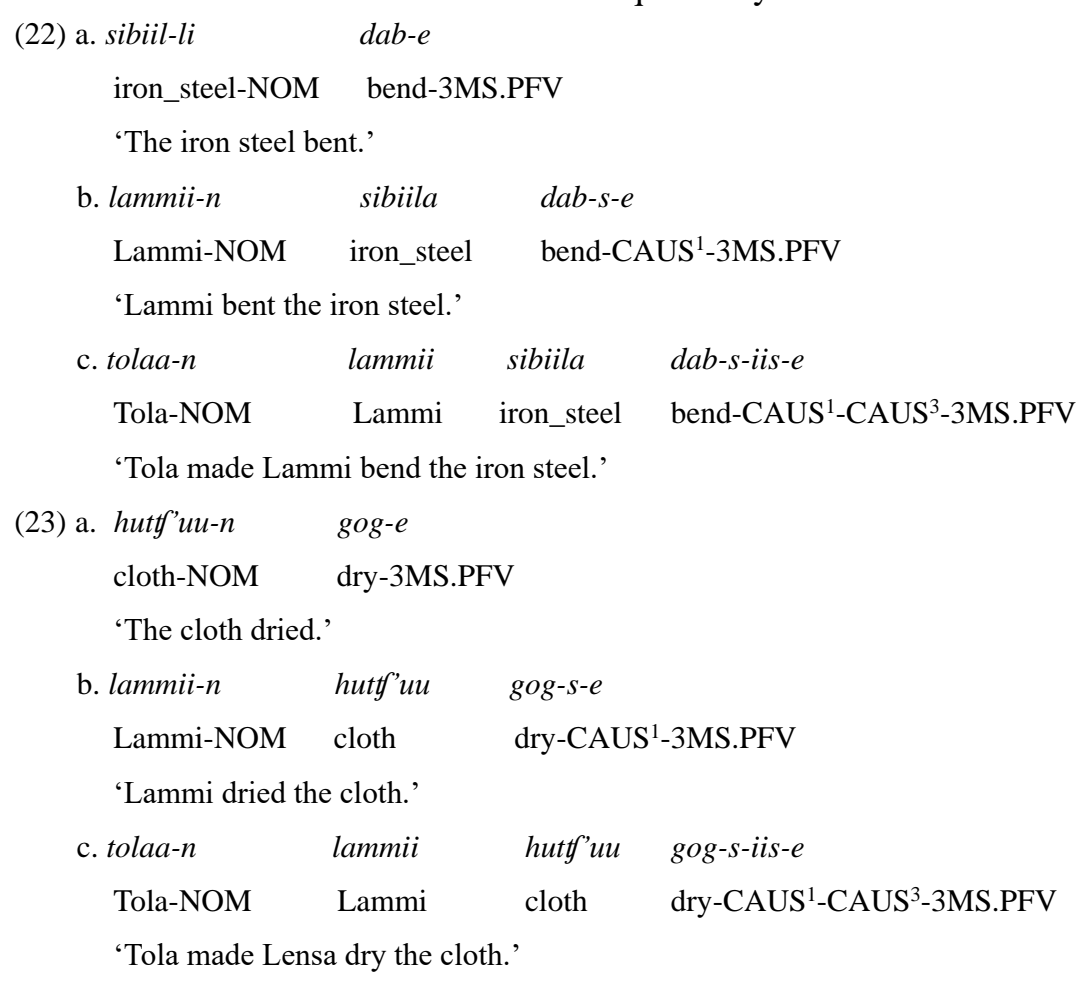

Examples (22a) and (23a) illustrate non-agentive intransitive verbs dab- 'bend' and gog'dry' respectively. These are non-causativized forms of the verbs, and are causativized by the suffixation of $-s$ and addition of leensaa 'Lensa' and lammii 'Lammi' in the first step (22b and 23b). They are, then, double causativized by the suffixation of -iis and addition of causers of macro-events, tolaa 'Tola' in (22c) and (23c). So, the actions of dabsiis- 'make bend' is performed by leensaa 'Lensa' through the order/cause of tolaa 'Tola', and the 
action of gogsiis- 'make dry' is accomplished by lammii 'Lammi' through the order of tolaa 'Tola'.

\subsubsection{Double causative -is+-iis [CAUS ${ }^{2}+\mathrm{CAUS}^{3}$ ]}

Another double causative structure is derived by suffixation of -is+-iis [CAUS ${ }^{2}+\mathrm{CAUS}^{3}$ ] (Dubnisky, Lloret \& Newman, 1988:487). This causative is structurally different from the former in that the first macro-event is indicated by agentive intransitive verbs in most cases, in addition to non-agentive intransitive verbs.

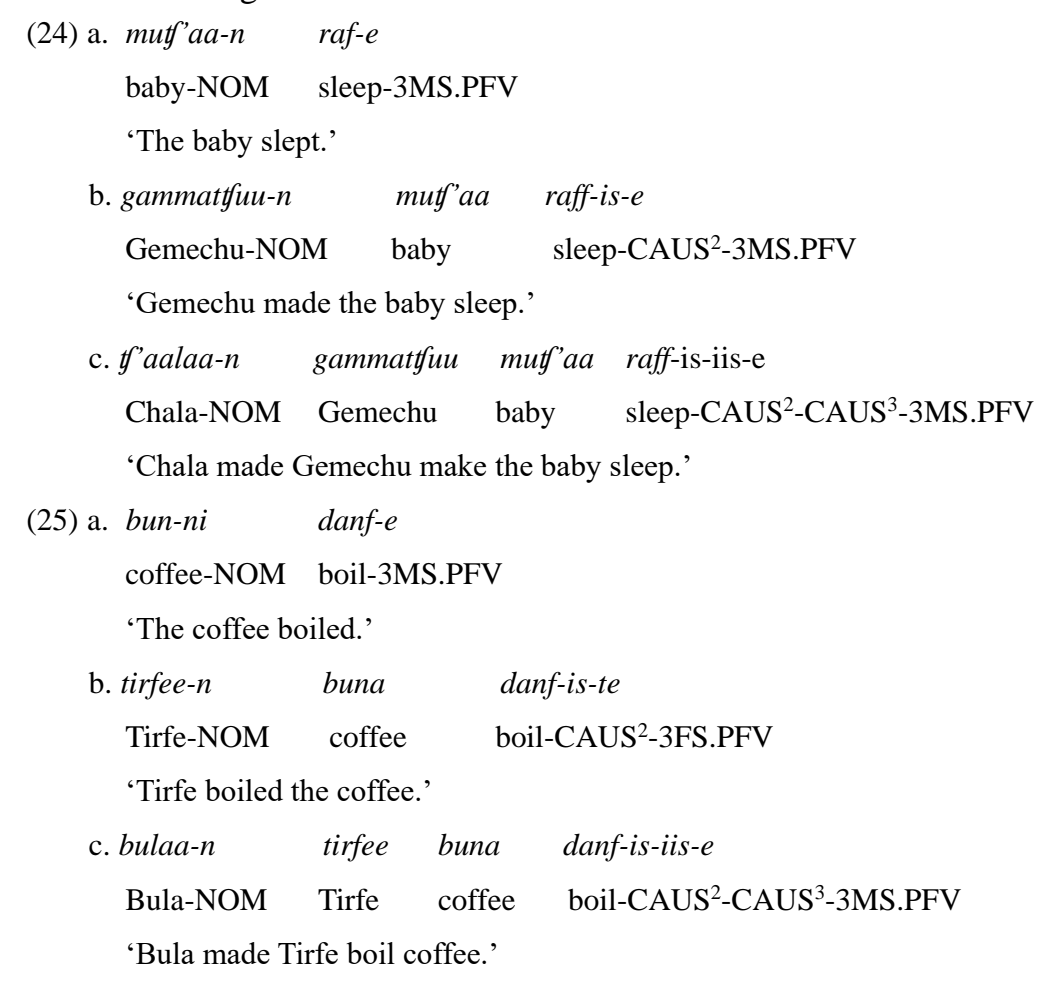

As shown in (24a), the agentive intransitive verb stem raf- 'sleep' is causativized by suffixing - $i$ s and by adding the causer gammatt uu 'Gemechu in (24b)'. And, the causative stem raffis- 'make sleep' is double causativized by suffixing -iis and by adding the external causer t'aalaa 'Chala' to result in raffisiis- 'make someone make sleep' as shown in (24c) above. In (25a), the non-agentive intransitive verb danf- 'boil' shows non-causativized structure, and this verb in (25b) attaches the causativizer -is and adds the agent tirfee 'Tirfe' to derive simple causative; and then, derive complex causative structure, danf-is-iis- 'make someone boil something', by attaching another suffix -iis and by adding indirect causer bulaa 'Bula' in (25c). The simple causative suffix -is [CAUS ${ }^{2}$ ] would seem to be phonologically conditioned allomorph of $-s\left[\mathrm{CAUS}^{1}\right]$ as the vowel $i$ can be claimed to be 
epenthetic to keep consonant cluster in the words; hence, $-s\left[\mathrm{CAUS}^{1}\right]$ is structurally the same as -is [CAUS ${ }^{2}$.

6.1.2.3 Double causative $-s+-i s$ [CAUS ${ }^{1}+\mathrm{CAUS}^{2}$ ]

Double causative structures can also be derived by suffixing the causative markers $-s+-i s$ $\left[\right.$ CAUS $\left.^{1}+\mathrm{CAUS}^{2}\right]$ and external causers accordingly. These suffixes are observed mostly to occur with agentive intransitive verbs and non-agentive intransitive verbs having CVVC, CVCVVC and some other verbs with long vowels. The following are two examples of such structures.

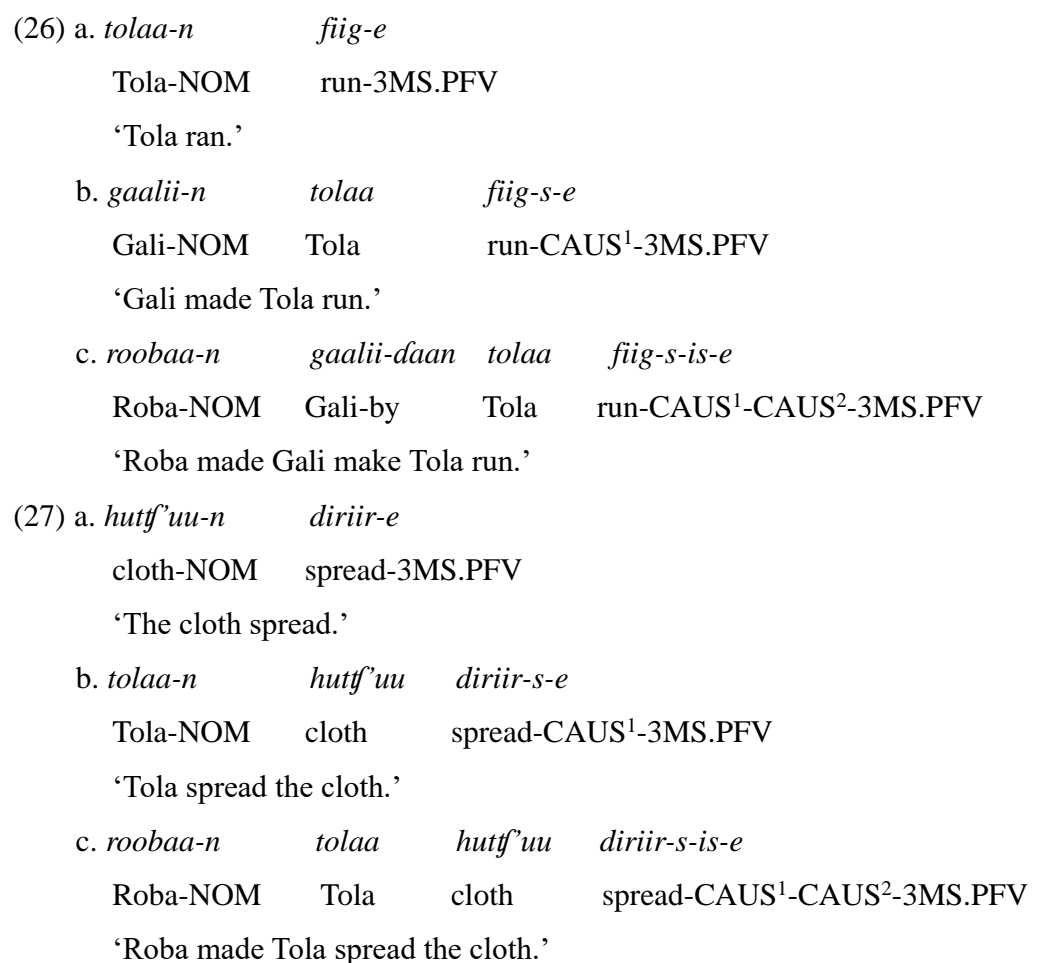

The agentive intransitive verb fiig- 'run' in (26a) is causativized by attaching suffix - $s$ and external causer roobaa 'Roba' in (26b). The causative verb fiig-s- 'make run' is further causativized by suffixing -is to derive fiig-s-is- 'make someone make run' as in (26c). Similarly, the non-agentive intransitive verb diriir- 'spread' in (27a) attaches the suffix -s to form simple causative diriir-s 'make spread' in (27b). Double causative form of the verb is derived by attaching the suffix -is with the respective argument/subject roobaa 'Roba' as in (27c). Hence, the causative marking suffixes and their arguments coincide.

6.1.2.4 Triple causative - $s+-i s+-i i s$ [CAUS ${ }^{1}+\mathrm{CAUS}^{2}+\mathrm{CAUS}^{3}$ ]

Triple causatives are derived by suffixation of three different suffixes on the 


\section{Causative Constructions in Afaan Oromoo: Formal and semantic perspectives}

non-causativized and causativized stems consecutively. The existence of triple causatives can be detected by providing sequences of causativization. Though double causative structures are commonly observed in Afaan Oromoo, triple and more complex causatives are rarely occurring despite their potential existence. The following are two example sentences with triple causative structures.



The examples in (28a) and (29a) show the non-agentive intransitive verbs $d a b$ - 'bend' and danf- 'boil', which are non-causativized. These verbs are causativized by suffixing $-s$ and -is, and adding subjects gurbaa 'boy' and bulaa 'Bula' to derive simple causatives as in (28b) and (29b) respectively. The simple causative verbs dabs- 'bend(tr.)' and danfis'boil(tr.)' are then double causativized by the marker -iis [CAUS ${ }^{3}$ ] and causers nam-ittf- 
'the man' and kamala 'Kemal' as in (28c) and (29c). The reason for the suffixation of -iis [CAUS ${ }^{3}$ ] with the causers of dabs- 'bend (tr.)' and 'danfis- 'boil (tr.)' is that there are no double causativized verbs *dab-sis- and *danf-isis-, but dab-s-iis- 'to make someone bend something' and danf-is-iis- 'to make someone boil something' in Afaan Oromoo. Thus, -is $\left[\mathrm{CAUS}^{2}\right]$ is the suffix attached preceding -iis [CAUS $\left.{ }^{3}\right]$ spatially (not temporally), with the external causers of the macro-events, kamaal 'Kemal' and ani 'I' as indicated in (28d) and (29d) respectively. Though there is possibility of extending the causative constructions beyond two by increasing the causations, only four or less participants/arguments are explicitly mentioned in the structures, but others are omitted. Generally, complex causatives, describing more than two macro-events, are strange despite the structural provision in the language.

6.1.2.5 Causative suffix -siis [CAUS ${ }^{5}$ ] with middle forms

The causative suffix -siis [CAUS ${ }^{5}$ ] is simple form which is affixed to stems of verbs, but as the verbs are derived mainly through the suffixation of middle form marker -at, the causation of middle verbs can be treated under complex causatives. The following examples illustrate the derivation of middle forms and the causativisation of the verbs.

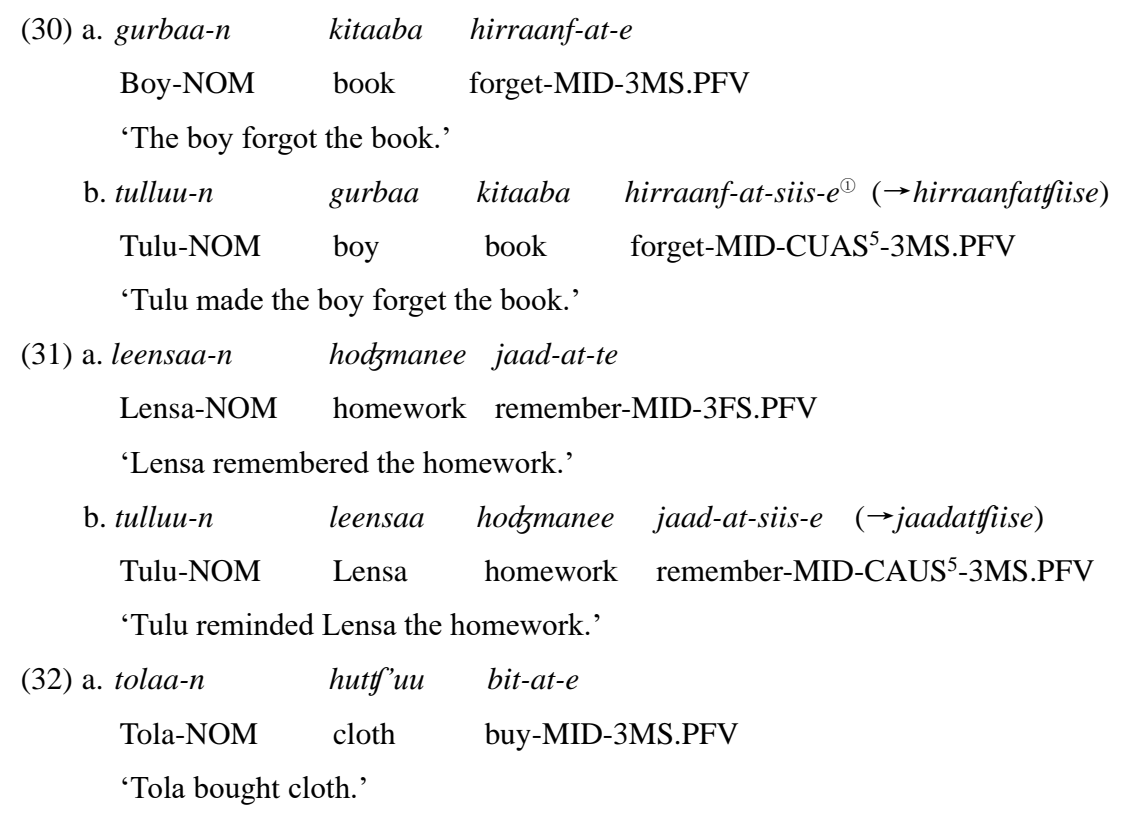

\footnotetext{
(1) After the causative suffix -siis is attached to the middle alternations, there is phonological process between $t$ and $s$ to produce $t$, affrication; hence, the words in the brackets are the surface structures obtained after the process.
} 
Causative Constructions in Afaan Oromoo: Formal and semantic perspectives

$\begin{array}{cccc}\text { b. margaa- } n & \text { tolaa } & \text { huty'uu } & \text { bit-at-siis-e }(\rightarrow \text { bitattiisee }) \\ \text { Marga-NOM } & \text { Tola } & \text { cloth } & \text { buy-MID-CAUS }{ }^{5} \text {-3MS.PFV }\end{array}$

'Marga made Tola buy cloth.' ('Marga caused/assisted to buy cloth.')

As observed in the examples (30a), (31a) and (32a), the verbs hirraanf- 'forget', jaad'remember' and bit- 'buy' attach the middle marker suffix -at to encode the experience/ action of the experiencers/agents in the sentences. The middle forms in (30b), (31b) and (32b) attach the causative suffix -siis [CAUS ${ }^{5}$ ] to form complex causatives. The causations show that the causers of the macro-events make the agents/subjects in the micro-events accomplish something for themselves, which can be considered as autobenefactive causatives.

\subsubsection{Subjectless causatives}

In Afaan Oromoo, certain derived causative verbs occur without an explicit causer subject in their constructions, in which they obligatorily inflect as default 3SM subject (Tolemariam, 2009:17). The causers are not physically explicit entities, but general known or not further specified circumstances as shown below.

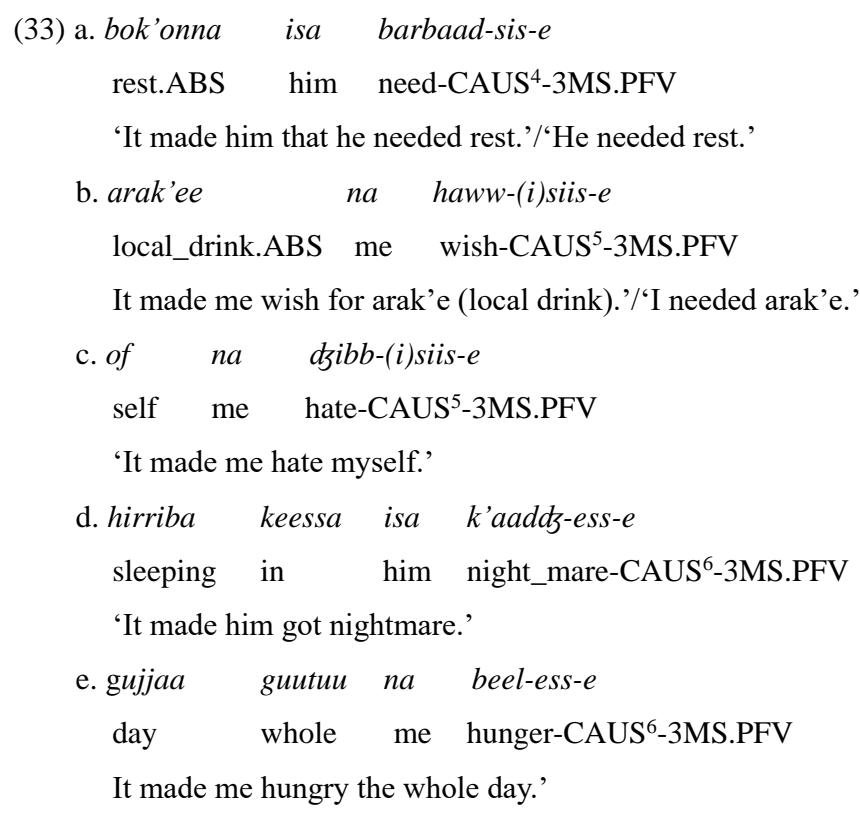

In (33a and b), the verbs lack a causer subject because the arguments bok'onnaa 'rest' and arak'ee 'local drink' are primary objects in the absolutive case, while the pronouns isa 'him' and $n a$ 'me' are secondary objects. Similarly, the causative sentences in (33c-e) have no external causers explicitly. Despite the causers, the speakers of the language understand 
from the structure that there is inanimate/unknown force which derives the experiencers/agents/subjects to feel/experience the encoded events/perceptions, which mainly reveal physiological/biological motives. In the causations, there is inverse relation between the causative suffixes illustrated above and the external/unknown causers, i.e., the causative suffixes are attached to the non-causativized verbs without valence-increment.

\subsection{Lexical and syntactic causatives}

Lexical causatives are structures which have inherently causativized verbs for non-causativized ones. These are mostly peripheral to languages of the world, but some languages have lexical items which encode causations. In Afaan Oromoo, there are verbs which inherently show causation of an action or change in state of affair of someone or something. Lexical causatives are peripheral structures of the language. The following are few examples.

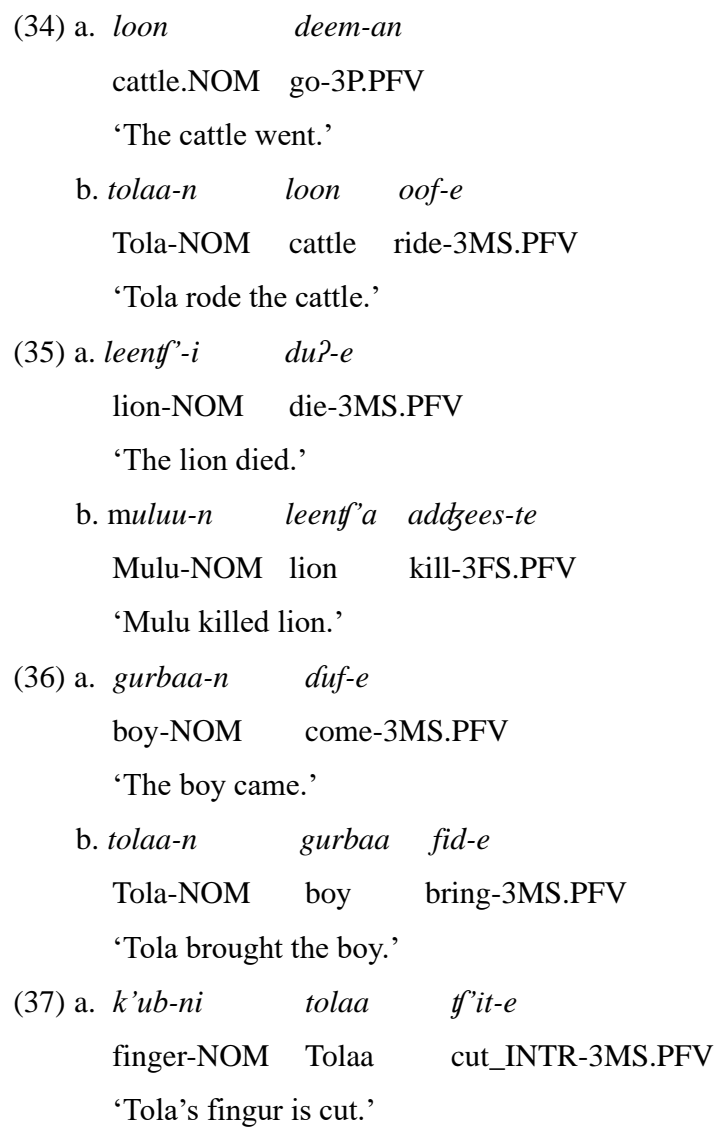


Causative Constructions in Afaan Oromoo: Formal and semantic perspectives

$\begin{array}{lrrl}\text { b. tolaa-n } & k \text { 'uba } & \text { isaa } & \text { kut-e } \\ \text { Tola-NOM finger } & \text { his } & \text { cut (tr.)-3MS.PFV } \\ \text { 'Tola cut his finger' } & & \end{array}$

(38) a. hodzii-n dum-e

job-NOM Finish_INTR-3MS.PFV

'The job is finished.'

b. tolaa-n hodzii fit'-e

Tola-NOM job finish-3MS.PFV

'Tola finished the job.'

The examples listed in (a) under 34-38 have agentive and non-agentive intransitive verbs deem- 'go', du?- 'die', duf- 'come', t'it- 'cut(intr.)' and dum- 'finish(intr.)', which are non-causative by their natures. However, those listed in (b) encode causative verbs as they show impositions of actions by the subjects/agents on the objects through the verbs ?oof'ride', addzees- 'kill', fid- 'bring', kut- 'cut' and fit'- 'finish' respectively. Thus, the verbs are naturally existing causative forms. By default, lexical causatives are categorized under transitive and ditransitive verbs in Afaan Oromoo, and they are typically in a suppletive relation with their non-causative counterparts.

Afaan Oromoo has often use syntactic (analytic) causative constructions which are highly peripheral. These are constructed by the verb god- 'make' and embedded subordinate clause introduced by the complementizer akka. Contrary to morphological productivity of causatives, the main reason for Afaan Oromoo to use syntactic (analytic) causatives is to show the intensities of the causes in the macro-events.

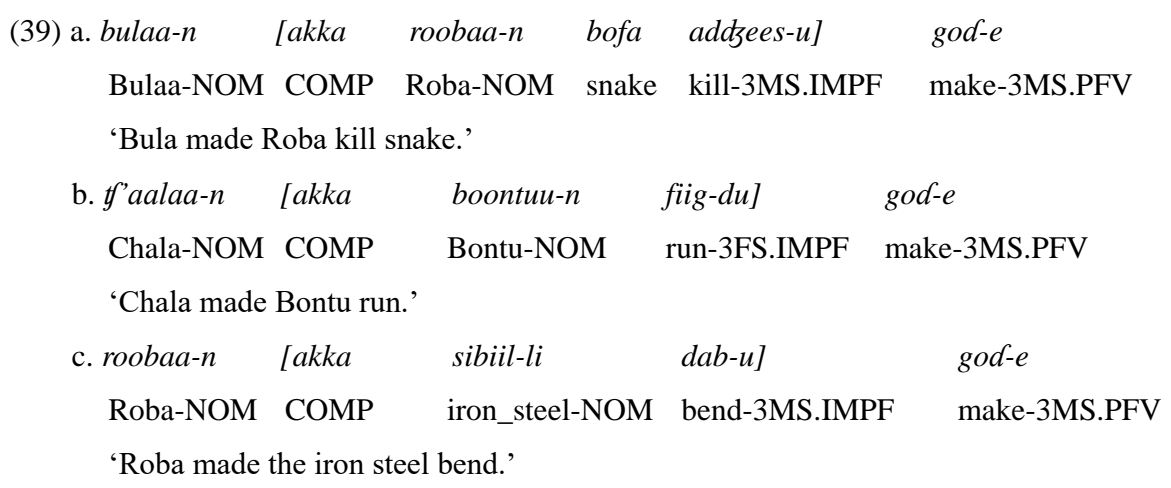

The syntactic (analytic) causative constructions in (39a) through (39c) have embedded subordinate clauses shown in square brackets. The arguments in the matrix clause and the embedded clause retain their nominative case marking, $-n$ on both causer arguments. The 
subjects of the embedded clauses are positioned in the square brackets next to the complementizer, but the subject of $g o d-e$ is found at the beginning of each sentence. Thus, the macro-event in the causative structure is indicated in the complement/matrix clause while the micro-event is shown in the embedded clause. Despite valence-increasing in syntactic (analytic) causative constructions, agentive intransitive in (39b) and non-agentive intransitive verbs in (39c) have less number of arguments than transitive in (39a) and ditransitive verbs.

One peculiar feature of syntactic (analytic) causation in Afaan Oromoo is that it can take morphological (synthetic) causativizers on matrix and embedded clauses simultaneously to derive double or triple causatives.

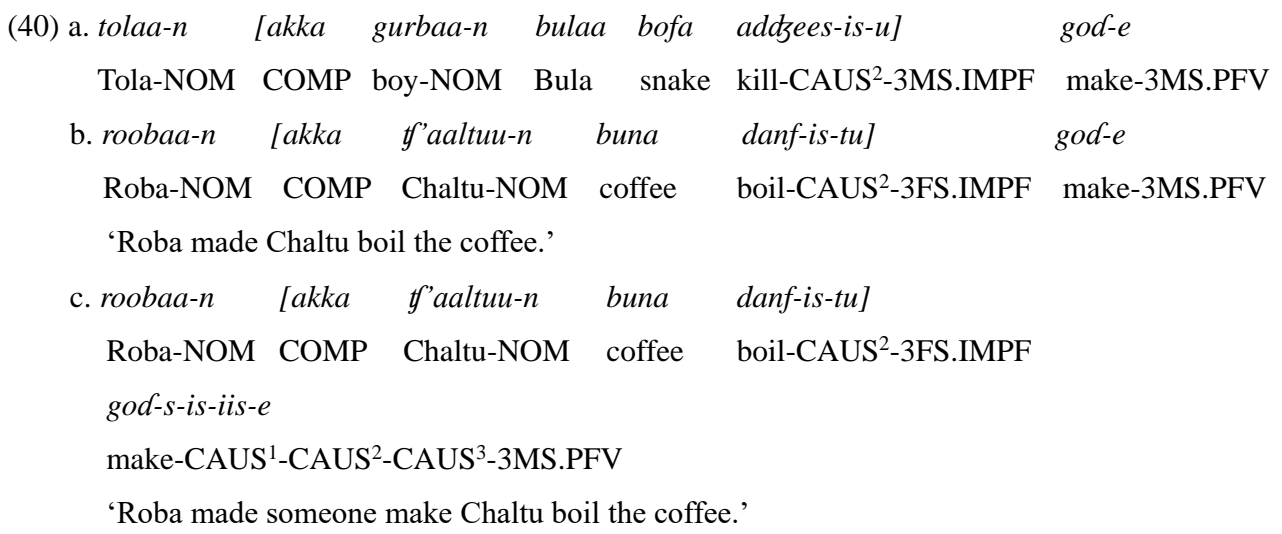

In (40a) and (40c), the structures show triple causatives. In the former, the double causative is derived by adding the argument gurbaa-n 'the boy' and by affixing -is to the verb addzees- 'kill', and triple causative is made through the addition of complement clause, the verb god-e 'made' with the argument tolaa-n 'Tola'. The later, (40c), is different from (40a) in that the verb god- 'make' in the matrix clause is causativized by triple causative suffixes, -s-is-iis whose arguments are not explicitly indicated in the structure. Similar to intransitive causatives and ideophonic verbalizing causatives, here too, there is triple causativization without valence-increasing. The example in (40b) is double causative derived through suffixation of -is on the verb danf- 'boil' of the embedded clause in single syntactic causative.

Generally, while morphological causatives reveal the process of causativization and the actions caused to happen, syntactic causatives show the explicit involvement of agents/causers in the micro- and macro-events. Hence, they encode the valents which involve directly and indirectly in the causations, and identify the responsible 


\section{Causative Constructions in Afaan Oromoo: Formal and semantic perspectives}

agents/arguments for the actions/happenings indicated in the transitivity.

6.3 Semantic features of causatives

Semantic features of causative constructions show the meaning or function encoded through the structures. There are a number of semantic causation types which mark different relations between cause and effect. In Afaan Oromoo, the most frequent semantic functions of causative constructions are direct vs. indirect and assistive causative (Tolemariam, 2009:20).

\subsubsection{Direct and indirect causatives}

As explained in conceptual perspective section, the distinction between direct and indirect causation hinges on the temporal distance between the causing event and the caused event. The two causatives are observed in Afaan Oromoo as in the examples below.

In Afaan Oromoo, the caused event of direct causation is temporally sequential to the causing event. There is no intervening or intermediary event that plays a role.

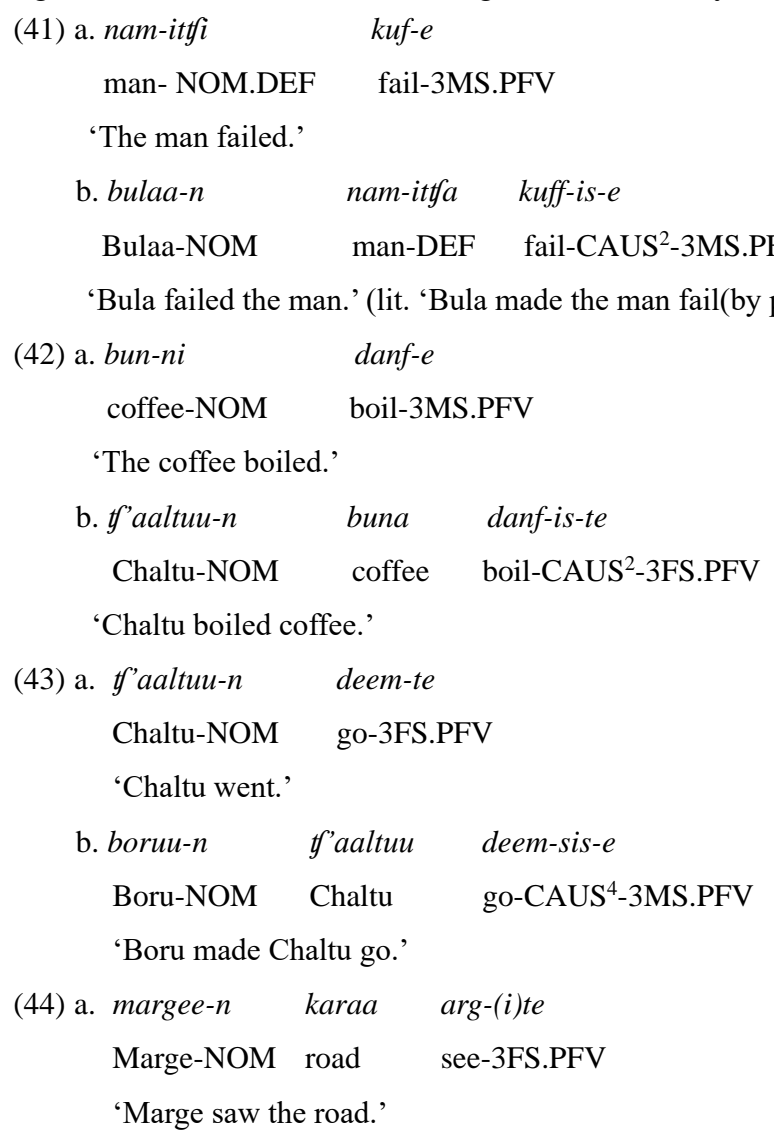


Eba Teresa Garoma \& Girma Tesfaye Tekle

\begin{tabular}{|c|c|c|c|}
\hline b. duulaa- $n$ & margee & karaa & $\arg -(i)$ siis-e \\
\hline Dula-NOM & Marge & road & see-CAUS ${ }^{5}-3 \mathrm{MS} . \mathrm{PFV}$ \\
\hline
\end{tabular}

As shown in (41-44), the performed actions or the changed state of affairs are indicated by direct causation of external arguments on the caused events of demoted subjects to object position. The causers or subjects of macro-events in (b) under the above examples, bulaa 'Bula', t'aaltuu 'Chaltu', boruu 'Boru' and duulaa 'Dula' have direct causes on nam-ittfa 'the man', buna 'coffee', ty'aaltuu 'Chaltu' and margee 'Marge' to perform the actions or to be in states of affairs indicated in the verbs kuff-is 'make fail', danf-is- 'make boil', deem-sis 'make go' and arg-(i)siis 'show, make see', respectively. In the language, simple causatives are direct causatives, and their suffixes correspond to them. Hence, they represent causative situations in which the causing events and the caused events adjoin temporally on each other, the former immediately preceding the latter.

Indirect causation, on the other hand, involves a situation in which the caused event does not immediately follow the causing event in temporal terms. So, there is an event intervening between the causing and caused events. The following causative constructions show indirect causation between the causer of the macro-events and the micro-events.

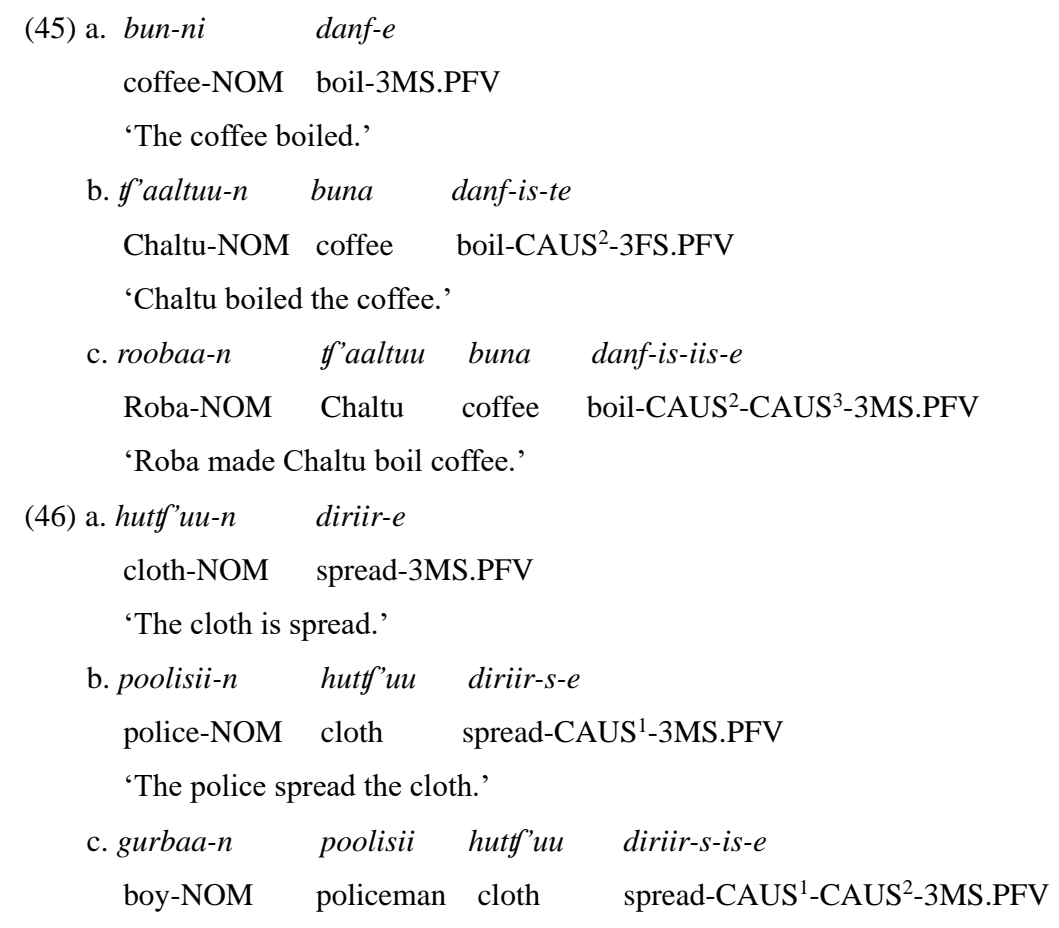




\section{Causative Constructions in Afaan Oromoo: Formal and semantic perspectives}

'The boy made the policeman spread the cloth.'

Examples (45a) and (46a) show non-causative actions as the verbs are intransitive, but those in (45b) and (48b) show direct causation because the agents act upon the actions/events. However, in examples (45c) and (46c), the micro-events (danf- 'boil' and diriir- 'spread') indicated in the verbs danf-is-iis 'make someone boil something' and diriir-s-is 'make someone spread something' have no temporal and spatial relations with the causers of macro-events, roobaa 'Roba' and gurbaa 'the boy'. The actions are performed by the causers/agents of the micro-events, ty'aaltuu 'Chaltu' and poolisii 'policeman'. So, there is indirect causation between the subjects/causers of macro-events and the micro-events, in which the causations are indicated by the suffixes -iis and -is on the two verbs, respectively. As the causative structures become complex (double, triple, etc.), their indirect causation or inaccessibility nature increases, and the causative suffixes correspond to them. Generally, it seems that the distinction between direct and indirect causations is basically expressed in morphology through simple and complex causative constructions. When a structure has simple causative forms, there is direct involvement of the causer while in complex causative, the causer of macro-event has no any temporal accessibility with micro-event.

\subsubsection{Assistive/Cooperative causatives}

Causative constructions, in Afaan Oromoo, can also show assistive/cooperative meanings. This is commonly observed in complex causatives, in which -siis [CAUS ${ }^{5}$ is attached to the middle suffix (Tolemariam, 2009:21).



\footnotetext{
(1) It shows the surface structure of the word after morphophonemic process (affrication due to $t-s$ interaction).
} 


\section{Eba Teresa Garoma \& Girma Tesfaye Tekle}

'My father assisted/helped me in buying cloth for myself.'

The most common and frequently observed middle marker in Afaan Oromoo is - at with phonological variants. The examples in (47a) and (48a) illustrate middle alternations in which the action/event encoded in the verb shows the auto-benefactive roles of the subjects after the suffixation of -at. When the arguments require assist/cooperation from external causers, the suffix -siis is attached to the middle forms, and the causer of macro-event that serves as assistant is added at the beginning of the sentences. Thus, bulaa 'Bula' and abbaa koo 'my father' play roles of assisting the subjects of the micro-events in (47b) and (48b), respectively.

\subsubsection{Pseudo-causatives}

In a strict sense, pseudo-causatives do not incorporate the meaning CAUSE, and thus, they do not belong to causatives, but their close relationship is obvious because they both involve the causative suffix (Tolemariam, 2009:22). In such construction, speakers paradoxically treat an entity in opposite or different manner which is not its quality; there is similation process. The suffix -eess $\left[\mathrm{CAUS}^{6}\right]$ is attached to adjectival and nominal stems with CVC and CVCC structures as shown below.

$$
\begin{aligned}
& \text { (49) a. bulaa- } n \text { kan-dijoo fag-eess-e-e Pilaal-a } \\
& \text { Bula-NOM COMP-near far-CAUS }{ }^{6}-3 \text { MS.PFV-CVB see-3MS.IMPF } \\
& \text { 'Bula sees something near as if it were far.'/'Bula is far sighted.' } \\
& \text { b. t'aalaa-n soba dugaa fakk-eess-e-e dubb-at-a } \\
& \text { Chala-NOM lie/false true picture-CAUS }{ }^{6}-3 \text { MS.PFV-CVB speak-MID-3MS.IMPF }
\end{aligned}
$$

In (49a), the subject bulaa 'Bula' considers something which is near or very short in distance as if it were too far or distant. The structure shows the far-sightedness of the viewer. In the second sentence, (49b), something false or lie appears to be true by the speaker. In both cases, the states of affairs in the sentences are assumed to be opposite state of affairs paradoxically.

\section{Conclusion}

This study has described formal/structural and semantic/functional types of causative constructions in Afaan Oromoo. Structurally, three types of causatives are identified: lexical, morphological (synthetic) and syntactic (analytic). The functional types of causatives detected in the language are direct, indirect, assistive and pseudo-causatives.

Morphologically, the language is detected to have simple causative suffixes: $-s$ [CAUS ${ }^{1}$ ], -is $\left[\mathrm{CAUS}^{2} / \mathrm{CAUS}^{7}\right]$, -iis $\left[\mathrm{CAUS}^{3}\right]$, -sis $\left[\mathrm{CAUS}^{4}\right]$, -siis $\left[\mathrm{CAUS}^{5}\right]$, and -eess [CAUS ${ }^{6}$ ]. 


\section{Causative Constructions in Afaan Oromoo: Formal and semantic perspectives}

These suffixes are attached to agentive intransitive, non-agentive intransitive and transitive verbs, and adjectival and nominal stems as well as ideophones. There are double and triple causative forming combinations of suffixes detected in this study: $-s+$-iis [CAUS ${ }^{1}+$ $\mathrm{CAUS}^{3}$ ], -is + -iis $\left[\mathrm{CAUS}^{2}+\mathrm{CAUS}^{3}\right.$ ], and $-s+-i s\left[\mathrm{CAUS}^{1}+\mathrm{CAUS}^{2}\right.$ ] are possible combinations of simple causative suffixes to derive double causatives, while $-s+-i s+-i i s$ [CAUS ${ }^{1}+$ $\left.\mathrm{CAUS}^{2}+\mathrm{CAUS}^{3}\right]$ is the only attested triple causative construction in Afaan Oromoo.

Lexically, there are verbs that can be analyzed as lexical causatives; most transitive and ditransitive verbs commit the speakers to the belief that a caused event has been realized after, and is wholly dependent on, the causing event expressed by the verb. Afaan Oromoo has also unproductive syntactic/analytic causatives in which the matrix clause and embedded subordinate clause with complementizer akka and god- 'make' are combined together. In addition, these causatives can further be re-causativized by suffixing the simple or complex causative suffixes on the verbs of micro-events and/or macro-events. The interaction of synthetic causatives makes the language derive morpho-syntactically complex causatives.

Although not exhaustively, the study has examined core semantic properties of causative constructions in Afaan Oromoo: direct, indirect, assistive and pseudo-causatives. Direct causatives are very frequent, but when the causation becomes complex, the indirect causative structures occur. Assistive and pseudo-causatives are often used in some constructions. There are features that are involved in causatives; subjectless causatives are frequent in the language. There are also intransitive causatives that show auto-benefactive case of the agents. Another typical feature is that the number of causative suffixes and causer subjects may not coincide when the intermediate subject in indirect causation is not worth mentioning.

Generally, Afaan Oromoo is one of the Lowland East Cushitic languages in which there are several ways of deriving causative structures. Causatives are morphologically highly productive and complex because they involve different voices (such as, active and middle), increase valences (arguments) with their causative suffixes in most cases, and show syntactically demoted and extensively demoted arguments as the nature of the causation becomes more complex. Besides, the morphological derivations of causative structures involve almost all types of verbs (transitive, ditransitive, agentive intransitive, non-agentive intransitive, inchoative stative, ideophones, etc.), adjectival and nominal stems along with different types of suffixes. Though causatives are not syntactically and semantically reach, there are causative constructions identified for the possibilities of having the structures. The lexical and syntactic (analytic) causatives are peripheral while morphological causative 
is central.

$\begin{array}{llll}\text { Abbreviations } & \\ \text { 3FS } & \text { Third Person Feminine Singular } & \text { CVB } & \text { Converb } \\ \text { 3MS } & \text { Third Person Masculine Singular } & \text { DAT } & \text { Dative } \\ \text { ABS } & \text { Absolutive } & \text { DEF } & \text { Definite } \\ \text { CAUS } & \text { Causative } & \text { DIM } & \text { Diminutive } \\ \text { CAUS1 } & \text { Causative one } & \text { IMPF } & \text { Imperfective } \\ \text { CAUS2 } & \text { Causative two } & \text { INTR } & \text { Intransitive } \\ \text { CAUS3 } & \text { Causative three } & \text { MID } & \text { Middle voice } \\ \text { CAUS4 } & \text { Causative four } & \text { NOM } & \text { Nominative } \\ \text { CAUS5 } & \text { Causative five } & \text { OLF } & \text { Oromo Liberation Front } \\ \text { CAUS6 } & \text { Causative six } & \text { PFV } & \text { Perfective } \\ \text { CAUS7 } & \text { Causative seven } & \text { PL } & \text { Plural } \\ \text { COMP } & \text { Complementizer } & & \end{array}$

\section{References}

Comrie, B. 1989. Language universals and linguistic typology [M]. Chicago: University of Chicago Press. CSA. 2007. Summary and statistical report of 2007 population and housing census of Ethiopia [M]. Addis Ababa: UNFPA.

Debela, G. 2010. The semantics of Oromo frontal adpositions[M]. Oslo: University of Oslo PhD Dissertation.

Dubnisky, S., M. R. Lloret \& P. Newman. 1988. Lexical and syntactic causatives in Oromo [J]. Language, 64(3): 485-500.

Escamilla, R. M. 2012. The syntactic causative construction in Hupa (California Athabaskan) [J]. Rice Working Papers in Linguistics, 3: 1-18.

Kebede, H. 2009. Towards the genetic classification of the Afaan Oromoo dialects [D]. PhD Dissertation. Oslo: University of Oslo.

Kulikov, L. 2001. Causatives [A]. In Martin Haspelmath, Ekkehard König, Wulf Oesterreicher \& Wolfgang Raible (eds.), Language typology and language universals [C]. Berlin: Walter de Gruyter, 886-895.

Lemmens, M. 1998. Lexical perspectives on transitivity and ergativity: Causative constructions in English [M]. Amsterdam: John Benjamins.

Mous, M. 2012. Cushitic [A]. In Zygmunt Frajzyngier \& Erin Shay (eds.), The Afroasiatic languages [C]. Cambridge: Cambridge University Press, 342-422.

Owens, J. 1985. A grammar of Harar Oromo [M]. Hamburg: Helmut, Buske.

Shibatani, M. 1973. Lexical versus analytical causatives in Korean [J]. Journal of Linguistics, 9: 281-297.

Shibatani, M. 2001. Introduction: Some basic issues in the grammar of causation [A]. In Masayoshi Shibatani (eds.), The grammar of causation and interpersonal manipulation $[\mathrm{C}]$. Amsterdam: John Benjamins, 1-22.

Stefanowitsch, A. 2001. Causative constructions in Akawaio [A]. In Masayoshi Shibatani (eds.), The grammar of causation and interpersonal manipulation [C]. Amsterdam: John Benjamins, 343-372.

Talmy, L. 2000. Towards a cognitive semantics: Concept structuring systems [M]. Cambridge: MIT Press.

Tolemariam, F. 2009. A typology of verbal derivation in Ethiopian Afro-Asiatic languages [M]. Utrecht: LOT.

Wierzbicka, A. 1980. Lingua mentalis: The semantics of natural language [M]. New York: Academic Press.

Yabe, T. 2007. The determinations of a phonological exponent of agentive $\mathrm{v}$ in the Oromo morphological causatives [J]. University of Pennsylvania Working Papers in Linguistics, 13(1): 435-448. 